\title{
Animals as Friends
}

\author{
Cynthia Townley \\ Philosophy Department \\ Macquarie University
}

\begin{abstract}
Whether animals, especially companion animals, count as friends depends on the conception of friendship as well as on the conception of animals. Some accounts of friendship can include (other than human) animals more easily than others. I present an argument in favour of characterising some animal-human connections as friendships, and address some of the standard objections to this characterisation. It might seem that under any conception of friendship, characterising animals as (potential) friends would likely lead to better treatment of animals, as various kinds of ill-treatment or use would not be consistent with treating someone as a friend. However, concern for animal welfare typically extends well beyond the direct concern for our own household companions, and is a concern for animals (or certain animals) in general, whereas friendship, by its nature, is particularist. There are limits to applying the concept of friendship to animal treatment beyond particular relationships.
\end{abstract}

\section{Introduction}

To some people, it is simply obvious that friendship with an animal is a full, even supreme, manifestation of everything friendship needs to be. Looking at actual relationships, it is hard to deny that the relationship to a non-human companion is the (equal) strongest connection in the lives of some humans, temporarily or permanently (for compelling fictional examples, see Auster 1999; Hornung 2010). But some people would judge the fact that a human's best friend really is a dog, cat or horse to be rather sad. They would think that friendship with an animal is, in some sense or other, weaker than, or inferior to the (possible) connections humans can cultivate together. There is no clear consensus about animals as friends.

I focus on companion animals, also known as pets, as these seem to be the clearest candidates for being called friends. Human-animal companionship, or pet-human cohabitation, is just one area of interaction between humans and animals, and it is not isolated from other areas. For example, a pet might be part of a clinical trial or a 
work of art. On a farm, an animal might spend part of its life as a pet, then become food or commodity, an assistance dog might retire as a pet. As Tony Milligan notes, in its rich sense, being a pet means much more than being a live animal purchased from a pet shop (Milligan 2009). The sense at issue here encompasses those creatures with whom humans can share some kind of reciprocal relationship. This is perhaps clearest with dogs and perhaps cats.

Some philosophical attention has been paid to animal-human friendship, but here, too there is little consensus. Some recent examples include Silke Shicktanz' discussion of a range of humananimal relationships including friendship, patronage and partnership models (Schicktanz 2006); Jeff Jordan's argument for vegetarianism based on the unacceptability of eating potential friends (Jordan 2001); Donna Haraway's extensive work on the overlap or mutual coconstruction of human and non-human lives, including a rich exploration of shared activities like dog agility work (Haraway 2007). Milligan has discussed animals and end of life decisions in ways that illuminate the depth of the connections between humans and animals, but resists calling these relationships "friendships" (Milligan 2009).

Thinking about animal and human friendships offers some potential for understanding animals including humans. Even if human and animal bonds are not friendships, they are interesting as relationships that involve affection and/or close and sympathetic attention. These might show up morally important features of the participants, because of the kind of attentive care involved. We can learn about our human selves from interaction with animals. In Freya Mathews' words:

emotional involvement with creatures who do not share our human goals and aspirations, our systems of values, enables us to gain an external perspective on those values. It enables us to appreciate how odd or arbitrary our human priorities might appear to non-human observers (Mathews 2007, 16). 
With respect to building understanding of animals, companionship can stand alongside the kind of close and long-term observation that ethologists recommend as basic to good information. Arguably, from the perspective of such relationships we are less likely to underestimate both the capacities of animals and, a moral leverage advocate might hope, undermine the associated view that (some) animals have lives that merit little or no protection (from killing, suffering, exploitation, disrespect and the like.) Satz, for example, discusses a non-discrimination approach to animal welfare (Satz 2006).

However, caution is warranted (Spencer, Decuypere, Aerts \& De Tavernier 2006; Tuan 1984). Pet owners might overestimate or distort the capacities of their animals (proximity does not guarantee a clear view, as the history of sexist and racist views demonstrates) and cruelty to companion animals is widespread. More radically, it has been argued that pets are not animals in their own right - they are human artefacts or creations. The cute, decorative, sentimentalised pets that sometimes show up with celebrities seem to support this view. However, this objection has two problems. First, it trades on a problematic view of an authentic animal, uninfluenced by its environment, human or otherwise. Second, as I will argue, humans are shaped by animals, too, and this mutual influence is an important aspect of animal-human friendship.

\section{Talking about Animals}

The main controversy about how to refer to household animals is not about calling my dog my "friend," but about the labels of "pet" and "owner". For example, PETA (People for Ethical Treatment of Animals) have argued against the institution of pet ownership, pointing out that it often fails to achieve high or even minimally decent standards of compassion and wellbeing. Some argue that the term "ownership" should be replaced by "guardianship" which better connotes the relevant responsibilities (Hankin, 2009). Some jurisdictions adopt language of animal companion, some vets replace "pets and owners" with "pets and guardians" or (in the case of my 
local vet) "pets and their people" which interestingly subverts the notion of ownership. The compatibility of these categories with friendship is complex, because guardianship and pet-hood are not relations of equals, and are irreducibly asymmetric. We can be mutual friends or companions, but not really each other's pets. Arguably, ownership and friendship can be compatible, but this does not make friendship and guardianship an easy fit. Ownership is a multi-stranded bundle of rights, and the bundle of rights and responsibilities of guardianship might fit differently with friendship.

Guardianship involves certain responsibilities, so it differs from typical friendship, which includes influence, but not a right to decide on behalf of the friend. Interestingly, there have been objections to the change in certain jurisdictions to "guardianship" language, often coming from veterinarian groups. This reflects a concern that the quite specific obligations of legal guardianship (in human cases) will carry over to the client who brings her animal to the vet - this seems a misguided concern as that interpretation is explicitly ruled out in much of the legislation (Satz, 2006).

Another objection to "pet" and preference for "guardian" is that pet lacks the connotations of welfare for the animal and might be consistent with "convenience euthanasia" whereas "guardian" carries the connotation of looking out for the other's welfare and interests. But Milligan sees the term differently: "The concept of pet, which plays a role within a life that is enriched by a relation to a non-human other, is one which involves treating (valuing) these animals as unique and irreplaceable creatures" (Milligan 2009, 406). A replaceable animal isn't a pet, neither is a disposable animal.

There does seem to be mutuality, both in affection and in shaping between pets and their people. Perhaps friendship requires mutuality, but not symmetry, and if so, pet-hood and friendship might be compatible.

Milligan opts for "guardianship" and "companionship" as the proper labels for dependent relationships between humans and 
animals. Like friendship, companionship involves some kind of reciprocity or mutual appreciation:

This reciprocity need not be understood as cognitively demanding for the animal. An animal guardian may be well aware that their lifelong companion's appreciation of the companionship is of a restricted sort. I will suggest that this supports the use of a terminology of companionship rather than friendship and that the latter involves a more demanding requirement of mutual understanding (Milligan 2009, 410).

Milligan sees the human-animal relationship as deeply valuable, his choice to avoid the term "friendship" does not at all indicate a dismissive or derogatory attitude. Milligan is quite clear that relationships with companion animals are morally serious, for example, in ways that preclude thinking of pets as simply replaceable. Conversely, some who accept the terminology of friendship seem to have a less robust view of (some dimensions of) their moral importance. Kristien Hens is comfortable saying that our relationships with animals (in particular dogs) can be friendships. However, she goes on to qualify these friendships. "Within a relationship of friendship, there are again major differences: dogs are only for a short period of time in our lives, they are to some extent replaceable and they are at our mercy with regard to medical care and euthanasia" (Hens 2009, 8). These differences show that there is no simple uncontroversial way to label the connections between humans and animals, as the terms can have different connotations.

Irreplaceability and uniqueness are important characteristics for relationships involving priority or partiality, whether these are termed friendly or companionate connections. Friendship is one such relationship, but so are family ties, and guardianships. Pets are, in the relevant sense, irreplaceable. Friends share non-substitutability with other relationships - family and other attachments, rivals and even enemies could be this way. So while showing non-substitutability does not suffice to show friendship, it appears that relationships with pets have at least some of the characteristics relevant to friendship. 


\section{Objections to Animal-Human Friendship}

The question about animal-human friendship is just not about the label, "friend," "pet" or "guardian," but about the intersection between the kind of relationship that friendship is, and the kinds of connection that (some) humans have with (some) animals. There are three main objections to taking animals to be full participants in friendships with humans: first, the power differential is too great; second, the cognitive demand of friendship exceeds animal capacities; and third, animals are not ethical agents in the requisite sense (perhaps because they lack the relevant cognitive capacities).

Does inequality of power preclude friendship? Human control over a pet is extensive. It includes when and what the pet eats, exercises, is located, breeds and so on. (This is related to seeing the pet as an artefact.) But animals who live in companionship with humans are not determined by human purposes. It might be 5 degrees at 6:30 am, and my dog expects a walk, and holds me to account for making that happen. In a friendship there is give and take, and this can take place between humans, and between humans and other critters. A refusal ever to be accountable and responsive would rule out friendship in both cases. So a provisional answer to the domination objection is that there can be sufficient mutuality, or give and take, for friendship. (When humans interact with independent or wild animals, it is quite clear, in some cases, that the animals are not dominated. Sometimes birds interact quite deliberately with humans, expressing preferences for some food over others, demanding attention and seeming to adopt unwanted behaviours if their demands are not satisfied. How close such connections can come to friendships is not clear, but they offer an example of animal-human connections that arise without household domination.)

The second objection is exemplified by Milligan's claim that friendship is cognitively demanding in a way that animal companions can't achieve (Milligan 2009). Accounts of friendship that involves sophisticated cognitive interpretation of the friend (Kennett and 
Cocking 1998) or a capacity to articulate principles will not be amenable to including (other than human) animals. Although the ascription of cognitive capacity to non-human animals varies, there are limits to what animals can do, or be seen to do. However, setting the cognitive bar very high will restrict the set of humans who can properly be said to participate in friendship, which is a version of the separation problem (the challenge of separating humans from other animals on moral grounds, or in relation to morally significant practices. See McMahan 2008). Younger children, among others, will not be friends. Alternatively including animals (and less sophisticated humans) as friends might inform an understanding of friendship, for example involving mutuality, but not an equality requirement for friendship (Goering 2003).

The final objection - that of moral agency - can be traced back to Aristotle, and remains a live objection in contemporary discussions. Jordan (2001) follows Aristotle's classic analysis of friendship in which we can be friends on the basis of pleasure, benefits or virtue. Jordan sees animal-human friendships as analogous to human-human friendships, and claims that it is uncontroversial that humans can befriend certain animals, in most of the ways that Aristotle describes.

Jordan argues that dogs can be friends with humans, and:

Since one can play with a dog, enjoy being with a dog, communicate with a dog, share things with a dog, do things with a dog, trust and be trusted by a dog and take care of a dog, it certainly looks as though one can be a companion-friend with a dog. Further, there appears no obvious reason to deny that one could even establish a utility-friendship, or a pleasure-friendship, with a dog. While it is true that one cannot establish a virtuefriendship with a dog, it does not follow that one cannot be a friend in any sense with a dog (Jordan 2001, 520).

According to Jordan, following Aristotle, in each case, we also are concerned for our friends, not for our own sake, but for the friend's sake. Many who share a household with a non-human critter 
would think they act for the pet's sake, and not all would always be deluded or self-deceived. In contrast, Spencer et al present an analogy between pets and other animals treated purely instrumentally (Spencer et al 2006). Spencer et al claim, for example, that a dog is forced to exercise at the owner's whim. But in my house, my dog wakes me up and demands a walk, and I comply. Admittedly, I could perhaps arrange things so I would not be disturbed in the early morning, but this pattern has emerged as part of our shared life. This is different from a use of an animal purely for human concern, for example, in laboratory testing. Some of each party's actions need to be plausibly called other-regarding, for example, as expressing affection. By these standards, humans and animals can be friends. There are no differences between dogs, cows, sheep, pigs and goats (and likely other animals) relevant to the possibility of befriending them, so humans can potentially befriend these animals too.

Of the range of friendships presented by Aristotle, Jordan concludes that only the virtuous friendship is unavailable. Here, again, it is the ascription (or non-ascription) of certain capacities to the animal that excludes it from this kind of friendship. (As Irwin points out, Aristotle excludes animals from choice, but not from voluntary action. For animals and children, actions can be voluntary, but not responsible. They can't have the ultimate rational desire for happiness - happiness as "the ultimate end that includes everything we have reason to choose for itself" (Irwin 1980, 129) and that means they can have only very limited decisions, not decisions about the whole of life.) The Aristotelian view of animals is echoed in Steven Sapontzis's argument that "while many of their actions are virtuous, animals are not moral beings because these actions are not part of a moral life" where a moral life is one in which one is aiming (at an individual or social level) towards some ideal (or morally better) way of life (Sapontzis 1980, 50). In order to have such a "program of fulfilling an ideal," (Sapontzis 1980, 50) a capacity for reflection is needed, but non-human animals don't show this. 
Perhaps Jordan and Sapontzis are too quick to conclude that no virtue friendship is possible between humans and others (see Ferguson 2004). Clearly (in my view) we can have affection and mutual benefit (Aristotle's pleasure and utility friendships). The capacity for reflective moral thinking, and character cultivation, in the way Aristotle explains the aspiration to live a good life is probably outside the repertoire of non-humans, but it is beyond many humans too. That bar seems excessively high, and I think many of my friendships don't involve that kind of deep or moralised conversation, even where it is possible in some sense that they might.

Animals seem capable of at least some degree of virtuous behaviour. Animals can exhibit compassion, bravery, loyalty and the like. One famous example is that of animals in experimental conditions who refuse to press the food bar if doing so will deliver a painful shock to a creature in the next cage, as well as the desirable pellet of food (Bekoff and Pierce 2009). If virtuous behaviour is possible, and a co-construction of some kind of shared life with goods for both parties seems to be possible with companion animals, then there is no reason to exclude animals from the whole domain of virtue friendships. At best, there is reason merely to concede that some friendships involve highly interpretative and articulate interaction of a kind that animals don't participate in. (The moral value of this practice is variable: eg exhaustive "workshopping" aspects of my life and my friend's, including various others with whom we interact could evoke more compassionate patient attitudes or be self-indulgent, arrogant backbiting. It is worth remembering that friendship can lead us morally astray (Cocking and Kennett 2000).)

Social support is one of the most often cited reasons for having a pet (Staatsa, Wallace and Anderson 2008). I think we can learn about resilience, joy, forgiveness and the like from animal companions, and in some ways animals might be very well placed to be moral exemplars. My cat is unimpressed by various superficial things like gadgets, fashion, status. “Animals are non-judgmental 
friends" (Mathews 2007, 16). Animals can respond to us in ways that differ from human responses, often on the basis of our kindness, sensitivity and responsiveness. (At the same time, one might think my cat is unashamedly out for what he can get, so I don't mean to romanticise his attitudes or character.) I surmise that benefits to humans from animal-human relationships can include moral benefits.

\section{Animals can be Friends, but the Moral Implications are Limited}

These considerations show that there is a plausible case for thinking (at least some) animals might be friends with humans, and that some important objections to this characterisation can be met. In some cases, it might be circumstances, luck or opportunity that dictate who our friends or companions can be. I suspect also that there are differences between persons- my capacity for friendship is best exercised in relations with non-humans, another person's is best expressed with other humans. If so, why think friendships between humans and non-humans are philosophically interesting, not just a topic of brute disagreement or human and non-human variability? For one thing, as the discussion shows, exploring the reasons why animals can or cannot be friends can shed light on interspecies relationships and on friendships and related concepts more generally.

However, acknowledging friendship with animals is less of an advantage for animals than might be hoped. It might seem obvious that friends are treated better than non-friends, so if animals are considered friends, they will be better treated. But the obviousness is

misleading here. Preferential treatment for friends does not extend to potential friends, but rather privileges one's actual friends. It is selective, and that is precisely why it can be a particularly problematic form of partiality.

Some thinkers have sought to derive moral leverage from taking animal-human friendships seriously: if people see animals as friends, we can be motivated to treat them better (non-instrumentally), for 
example, restricting or ruling out certain research or food purposes. Jordan uses a friendship argument to argue for vegetarianism, and concludes that it is wrong to eat such animals, just as it is (under normal circumstances) wrong to eat one's friends (Jordan 2001). He shows that "if something is a possible friend...it is not a morally permissible foodstuff" and concludes in favour of vegetarianism (Jordan 2001, 311). The vegetarianism may be restricted - perhaps there are some animals that can't be friends, and if so, it may be permissible that that one might eat them. Perhaps oysters or snails would be candidates.

These kinds of "pure use" relationships with animals in which animals are treated more or less like things manifest at best indifference to the particular animal in question. Many animals used for food, breeding or in laboratories are treated as interchangeable, even disposable. The indifference to the well-being of the animals in question can amount to cruelty. The moral leverage thought is that seeing animals as friends might preclude this kind of attitude and the treatment it licenses. One reason it seems promising is that some species (including rats, dogs, rabbits) are found in family-household relations as well as "use" or exploitation contexts.

Rosemary Rodd offers a second example. "Once one has seen a particular animal as a friendly individual it no longer becomes easy to regard another individual animal as a laboratory 'tool"' (Rodd 1985, 54). Here, Rodd is pointing to a tension between having a relationship based on a unique inherent value of an animal (pet, friend, companion) and being able to treat a very similar animal purely instrumentally. Becoming an animal experimenter often requires the adoption of that latter view. Rodd argues that there may be risks in overcoming a "sentimental" sympathy for animals in order to overcome common scruples and inhibitions against using them in at least some kinds of experimental ways (Rodd 1985; see also McLean 2009).

While the inconsistency shown to companions on one hand and beasts of burden, use, consumption, and pests on the other attracts 
significant criticism, there is a pragmatic objection to the moral leverage argument: we don't seem to have progressed very far towards consistent conduct. As humans, we are good at inconsistency, bad at consistency, so an appeal to consistency seems unlikely to engender much change. In any case, a deeper problem is that friendship seems to be about partial and preferential rather than consistent treatment, so it isn't the right conceptual mechanism to motivate a general concern.

To see this, consider again Jeff Jordan's initially persuasive moral leverage argument (Jordan 2001). It is unacceptable (under normal conditions, for which read there are no urgent survival needs) to eat one's friends. Many (if not all) commonly consumed animal species are as capable of friendship with humans as are dogs. (Pigs, cows, chickens and sheep can have affectionate, playful connections). So we should not be eating those animals. Humans who are omnivores and for whom consuming animal flesh is not an urgent survival need should not eat meat. We are unlike wild predators who must eat meat or perish (compare Everett 2001, and Shapiro 2006).

As indicated by Jordan's title "Friends should not let friends be eaten," the implications go further than human vegetarianism. Suppose some of our domestic animals are both friends and obligate carnivores. Suppose my cat and dog don't and can't thrive on a vegan diet in the way that I can. I am in charge of providing for their needs - they eat what they are given, they are given what I purchase for them. If the moral leverage argument worked, a paradoxical result would arise: friendship requires you to do (use animals as food) what friendship prohibits (use animals as food). And friendship licenses at least some partiality and preference for one's actual friends above potential friends, so the conclusion about general treatment is problematic, or the argument requires me to abandon friendship with obligate carnivores such as cats. While I don't accept the moral leverage argument for vegetarianism, to the extent that there are compelling reasons for vegetarianism, the paradox might be avoidable, but not the problem. The moral cost of my friendships 
with animal companions is that I am implicated in the morally unjustified practice of treating potential friends as food.

Rodd's argument applies to actual encounters with animals and in these cases, extending one's friendly attitude to interactions could support behavioural change (Rodd 1985). But reservations remain because humans so easily compartmentalise our attitudes, and on the whole we seem more likely to use our capacity for reason to rationalise convenient conduct than to lift our moral game. While animals can be our friends, that result does not do them as much good as has been hoped.

\section{References}

Auster, Paul. 1999. Timbuktu New York: Picador.

Bekoff, Marc and Jessica Pierce. 2009. Wild justice: The moral lives of animals. Chicago and London: University of Chicago Press.

Cocking, Dean and Jeanette Kennett. 2000. Friendship and moral danger. The J ournal of Philosophy 97 (5): 278-296.

Everett, Jennifer. 2001. Environmental ethics, animal welfarism, and the problem of predation: A Bambi lover's respect for nature. Ethics \& the Environment 6 (1): 42-67.

Ferguson, Kieran. 2004. I [heart] my dog. Political Theory 32 (3): 373-395.

Goering, Sara. 2003. Choosing our friends: Moral partiality and the value of Diversity. J ournal of Social Philosophy 34 (3): 400413 .

Hamington, Maurice. 2008. Learning ethics from our relationships with animals: Moral imagination. International J ournal of Applied Philosophy 22 (2): 177-188.

Hankin, Susan J. 2009. Making decisions about our animals' health care: Does it matter whether we are owners or guardians? Stanford J ournal of Animal Law and Policy 2: 1-51

Haraway, Donna. 2007. When species meet. Minneapolis\& London: University of Minnesota Press. 
Hens, Kristien. 2009. Ethical responsibilities towards dogs: An inquiry into the dog-human relationship. J ournal of Agricultural and Environmental Ethics 22: 3-14.

Hornung, Eva. 2010. Dog boy. New York: Viking.

Irwin, T. H. 1980. Reason and responsibility in Aristotle in Essays on Aristotle's Ethics, ed. A. Rorty. Berkeley and Los Angeles: University of California Press.

Jordan, Jeff. 2001. Why friends shouldn't let friends be eaten. Social Theory and Practice 27 (2): 309-322.

Kennett, Jeanette and Dean Cocking. 1998. Friendship and the self. Ethics 108: 502-527

Mathews, Freya. 2007. Without animals life is not worth living. Between the Species VII. http://cla.calpoly.edu/bts/

McLean, Lesley. 2009. How ought we to live with nonhuman animals? Peter Singer's answer: Animal liberation parts I \& II. Between the Species IX http://cla.calpoly.edu/bts/

McMahan, Jeff. 2008. Challenges to human equality. TheJ ournal of Ethics 12: 81-104.

Milligan, Tony. 2009. Dependent companions. Journal of Applied Philosophy 26 (4): 402-413.

Rodd, Rosemary. 1985. Pacifism and absolute rights for animals: A comparison of difficulties. J ournal of Applied Philosophy 2 (1): $53-61$.

Staatsa, Sara, Heidi Wallace, and Tara Anderson. 2008. Reasons for companion animal guardianship (pet ownership) from two populations. Society and Animals 16: 279291www.brill.nl/soan

Sapontzis, S. F. 1980. Are animals moral beings? American Philosophical Quarterly 17 (1): 45-52.

Satz, Ani B. 2006. Would Rosa Parks wear fur? J ournal of Animal Law and Ethics 101: 139-160.

Schicktanz, Silke. 2006. Ethical considerations of the human-animalrelationship under conditions of asymmetry and ambivalence. J ournal of Agricultural and Environmental Ethics 19: 7-16.

Shapiro, Paul. 2006. Moral agency in other animals. Theoretical Medicine and Bioethics 27: 357-373 
Spencer, Stuart and Eddy Decuypere, Stefan Aerts, and Johan De Tavernier. 2006. History and ethics of keeping pets:

Comparison with farm animals. J ournal of Agricultural and Environmental Ethics 19: 17-25.

Tuan, Yi Fu. 1984. Dominance and affection: The making of pets. New Haven \& London: Yale University Press. 